\title{
\& Research Square

\section{Effectiveness of task-sharing in providing comprehensive long-acting reversible contraceptives through Level IV health extension workers in rural Ethiopia}

Alula Teklu ( $\square$ ateklu72@gmail.com )

MERQ PLC https://orcid.org/0000-0001-7321-2838

Awol Seid

EPHA

Kassahun Mormu

David and Lucile Packard Foundation

Tesfa Demlew

EPHA

Ephrem Tekle

$\mathrm{FMOH}$

Berhane Assefa

$\mathrm{FMOH}$

Simegnew Alem

EPHA

Girmay Medhin

Addis Ababa University

Kesetebirhan Delele

FHI: FHI 360

Teklemichael G. Tesfay

Wolkite University

Research

Keywords: LARCs, HEWs, IUCD and Implanon, demographic, socioeconomic characteristics, reproductive history

Posted Date: September 7th, 2021

DOl: https://doi.org/10.21203/rs.3.rs-842200/v1 
License: (c) (i) This work is licensed under a Creative Commons Attribution 4.0 International License. Read Full License 


\section{Abstract}

Background: Modern family planning uptake in Ethiopia, primarily short-acting injectables, has increased after the engagement of community health extension workers (HEWs). The aim of this study was to investigate the effectiveness of using Level IV health extension workers to deliver long-acting reversible contraceptives (LARCs) at the community level.

Methods: A retrospective cohort study design was used to recruit 710 women who received LARC insertion services at pilot health posts within eight months before survey time. The interviewer administered a data collection tool to collect the required data through a house-to-house survey. The questionnaire had sections covering demographic and socioeconomic characteristics, reproductive history, use of family planning methods, knowledge about LARC methods (i.e., IUCD and Implanon), and service satisfaction. Descriptive statistics were used to analyze data. Chi-square test was used to identify the determinants of LARC use.

Results: Out of 702 LARC users included in the study, $92.7 \%$ received services from Level IV HEWs. The median age of clients was 30 years (IQR: $25-35)$, $92.7 \%$ were married, and $22.6 \%$ were new family planning users ( $75 \%$ Implanon users and $19.4 \%$ Jaddelle users). Of the aggregated variables, $67.38 \%$ had good knowledge of LARC, $92.28 \%$ had positive attitudes in availing services at health posts, and $92.76 \%$ was the satisfaction score of clients. New users tended to be young, Muslim, less likely to want more children, and more likely to decide on contraception on their own.

At eight months post insertion, LARC use was effective in preventing pregnancy (99.7\%) with low removal $(n=36,5.1 \%)$ and expulsion rates $(n=1,0.1 \%)$. No infection was reported. The major reasons for removal were side effects and the desire to have children. Client knowledge, attitude, and satisfaction were found to be high.

In conclusion, trained Level IV HEWs provided LARCs safely and effectively at the health post level as an alternative service delivery outlet.

\section{Plain English Summary}

Provision of family planning services has been hampered because of lack of access to rural residents in Ethiopia. This is especially true for LARC which are only available at higher level health facilites which are not easily accessible. Use of the closest outlets to the community for LARC service delivery was considered. There was paucity of evidence on the safety and effectiveness.

A pilot program where L4HEW were trained to provide comprehensive LARC services was initiated, with the objective of assessing its safety and effectiveness. Women from within the catchment population, who chose to receive the service at the HP level were provided. 
A retrospective cohort study design, where more than 710 women who received the services in the last 8 months, was used to determine safety and effectiveness. The mothers were identified using the registers at the health post level. All users were asked about their experiences in terms of pregnancy, side effect, expulsion and other events.

Out of the 702 women who responded to the questions, only 1 reported pregrancy which is $0.3 \%, 92 \%$ reported satisfaction by the service and the same proportion approved delivery of the LARC services by the L4HEW. Removal was done for $5.1 \%$ and there were no infections reported in the study period.

Provision of comprehensive LARC by L4HEW at the HP level is safe and effective. Expansion to more HP is recommended.

\section{Introduction}

With a population that just crossed the 100 million mark, a total fertility rate of 4.6 , and a contraceptive prevalence rate of $36 \%$, Ethiopia is the second most populous country in Africa. The population is expected to reach 138 million in the coming 10 years [1].

Although there have been remarkable improvements in the uptake of family planning services in Ethiopia, the urban-rural disparity and the skewed method mix call for more innovative approaches [2]. In a facility survey done by Performance Monitoring and Accountability 2020 (PMA2020), 84\% of health posts provide three family planning methods, while $88 \%$ of health centers and $95 \%$ of hospitals provide five or more [3].

In the past 15 years, the most preferred family planning method in Ethiopia was the injectable (DepoProvera), and its uptake has increased by more than tenfold in the same period [2]. A review of the four rounds of PMA2020 showed that instances of the injectable family planning method remained high at $64.5 \%$ although its share has declined from $74.1 \%$ in 2011 . During the same period, the percentage of Implanon use increased from $16.3-24.2 \%$. Of all the family planning methods, the line share of intrauterine contraceptive devices (IUCDs) remained extremely low at 2\% [3-6].

Utilization of long-acting reversible contraceptives (LARCs) was increasing at an extremely low rate until 2016 when it reached $7.9 \%$ primarily because of the involvement of health extension workers (HEWs) in this service, who administered one million implants [7]. Meanwhile, data from the Ethiopian Demographic Health Survey (EDHS) in 2016 showed that injectable family planning methods account for around 64\%, used by married women, and permanent methods remain at close-to-zero status [2]. The trends in the use of modern family planning methods as evidenced by the EDHS report from 2000 to 2016 increased from $6 \%$ in 2000 to $36 \%$ in 2016, and injectable contraception accounts for two-thirds of the increase followed by implants only at around one-third $[8,9]$.

The government of Ethiopia has implemented family planning (FP) as a strategy to improve maternal and child health and bring about overall development [10]. Accordingly, programs are being implemented 
to increase access to and demand for quality FP services through the expansion of the contraceptive method emphasizing long-acting methods at lower-level service delivery points [11]. As part of this strategy, the Federal Ministry of Health $(\mathrm{FMOH})$ is implementing Implanon and IUCD scale-up initiatives in the country [12]. The aim is to expand voluntary access to long-acting FP methods at the lowest level of health service post; therefore, increasing the method choices available to remote and rural communities is important to improve maternal and child health.

Using the Health Extension Program (HEP) as a platform, the government began expanding FP options in 2009 with subdermal insertions of Implanon by HEWs at health posts [8]. It has now started an initiative to bring LARCs closer to remote and rural communities by training Level IV HEWs (L4HEWs) on the insertion and removal of IUCDs and performing implants at the health post level [13]. This is an additional task-shifting to HEWs, which is in line with the World Health Organization's (WHO) task-shifting recommendations and guidelines for auxiliary nurses for IUCD insertion and removal [14]. In the WHO's task-shifting recommendations, while allowing consideration of task-shifting for IUCD insertion, it requires rigorous research to supplement weak existing evidence [14]. Thus, the $\mathrm{FMOH}$ introduced the task-shifting program as a pilot study in 66 health posts. The primary aim of the pilot program was to effectively and safely examine the service provision of LARCs, specifically Implanon and IUCDs, at health posts by L4HEWs as task-sharing. Therefore, the study was done to evaluate the pilot program by examining the user-level effectiveness of the LARC service provision by L4HEWs at health posts.

\section{Material And Methods}

\section{Study area and period}

Administratively, Ethiopia is divided into nine federal regional states and two chartered cities. There are five agrarian, two pastoralists, two emerging regions, and two chartered cities [15]. Each regional state is divided into zones, and each zone is divided into districts or Woreda. The lowest government budgetary and administrative structure is the Woreda although each Woreda is divided into several administrative structures called Kebele.

Access to adequate healthcare is particularly challenging in all nonurban settings. The healthcare delivery system in Ethiopia is organized in a three-tier system. The primary level in rural settings includes health posts linked with health centers and a primary hospital. In the urban setting, the health center is the primary entry point into the health system. As more than $80 \%$ of the Ethiopian population resides in the rural part of the country, health posts are the primary entry points of this population, and they are located at the geographic center of each Kebele. One health post is expected to serve a total population of 5,000, although this may vary based on the settings [16].

Health posts are expected to provide primarily preventive services focused on maternal and child health services, hygiene and sanitation, and communicable disease prevention [16]. All health posts have at least two HEWs who are trained for one, two, or three years and certified as Level I, Level II, or Level III, 
respectively. L4HEWs, introduced in 2016, are trained for one more year after graduating as Level III HEWs and serving for at least two years.

The provision of LARCs was initiated in selected health posts with at least one L4HEW in four agrarian regions at the end of 2016. These regions are Tigrai, Amhara, Southern Nations Nationalities and Peoples Region (SNNPR), and Oromia. During the survey, there were 66 health posts (20 in Tigrai, 19 in SNNPR, 14 in Amhara, and 13 in Oromia) that started providing LARCs. Out of these, 52 health posts were included in this study. Data were collected from April 12 to May 5, 2017.

\section{Study design, population, and sample size}

This study was done using a retrospective cohort study design. Sample size was determined using discontinuation as a binary outcome with an assumption of $16 \%$ discontinuation of LARCs in one year, $3 \%$ margin of error, $95 \%$ confidence interval, $2 \%$ design effect, and $10 \%$ non-response. Accordingly, the sample size of 710 women study subjects recruited from each health post was determined using the "probability proportional to size" approach using the reported number of women who received LARCs as a measure of size. All women who received LARC insertion services at the pilot health post within eight months before the survey were eligible for the study. The list of users extracted from the registers of the target health post was used as a sampling frame.

\section{Data collection instrument}

Taking the EDHS 2016 questionnaire as a starting point [17], the instrument was developed with potential outcomes, user satisfaction, and knowledge about family planning methods and their side effects. This questionnaire has seven sections covering demographic and socioeconomic characteristics, reproductive history, use of family planning methods, knowledge about LARC methods (i.e., IUCD and implants), and service satisfaction. After inversely coding negatively assessed questions, five aggregated variables were generated from the collected data, which includes wealth index and knowledge about IUCDs (six items) and implants (seven items), with "yes" or "no" responses in which those who scored above the median were considered as having good knowledge; clients' satisfaction with the service, assessed by seven items on a Likert scale in which those who scored above the median were considered as satisfied with the service provision; and attitudes about LARCs, measured by six statements on a five-point Likert scale in which those who scored above the median were considered as having positive attitudes while those scored less than the median were considered as having negative attitudes toward the service. Furthermore, for the reliability test, a Cronbach's alpha coefficient of 0.70 and above was accepted.

\section{Data collection and quality assurance}

A total of sixteen nurses and four supervisors (four teams of five, one team per region for the four regions, each team with four data collectors and one supervisor) were used for field data collection. All were trained for three days on the data collection tool. Following a line-by-line review of the tool, mock interviews with each other and a one-day field pretesting were prepared as part of the training. The tool was refined following its pretest, and feedback was also given to the data collectors on issues that 
required further clarifications. Completeness of the questionnaires, timing, and logical errors were followed by the supervisors. Missing data were completed immediately by revisiting the household. Double data entry was done on $10 \%$ of the completed data to check for entry-related errors.

\section{Data management and statistical analysis}

The data were coded and entered into a template using Microsoft Office Access 2013 for Windows. The cleaned dataset was then exported to STATA version 14 for analysis. The electronic data was then examined for incompleteness, inconsistency, and unexpected responses by running frequencies and cross-tabulations of selected variables. Descriptive analysis of each variable was used for preliminary examination of findings. Frequency and percentage were used to describe various characteristics of the study participants. Demographics and reproductive history were taken as independent variables while access to modern family planning only at the health posts, decision-making on the use of family planning (self vs. jointly with husband or partner), and LARC users were primary outcome variables. Chisquare was used to assess associations between being a LARC user and different characteristics. Pvalues below $5 \%$ were used as statistical significance.

\section{Results}

\section{Background characteristics}

Majority of the respondents were within the age range of $20-34$, and only $2.7 \%$ were under 20 years old, $92.7 \%$ were currently married, $61.0 \%$ were literate, $75.0 \%$ have literate partners (Table 1 ). 
Table 1

Baseline characteristics of study participants, $n=702$, Ethiopia

\begin{tabular}{|c|c|c|}
\hline Characteristics & Number & Percent \\
\hline \multicolumn{3}{|l|}{ Age $(n=699)$} \\
\hline$<20$ & 19 & 2.7 \\
\hline $20-35$ & 488 & 69.8 \\
\hline$>35$ & 192 & 27.5 \\
\hline \multicolumn{3}{|l|}{ Religion } \\
\hline Christian & 418 & 59.5 \\
\hline Muslim & 284 & 40.5 \\
\hline \multicolumn{3}{|l|}{ Occupation } \\
\hline Housewife & 368 & 52.4 \\
\hline Farmer & 219 & 31.2 \\
\hline Other & 115 & 16.4 \\
\hline \multicolumn{3}{|c|}{ Having past pregnancy } \\
\hline No & 17 & 2.4 \\
\hline Yes & 685 & 97.6 \\
\hline \multicolumn{3}{|c|}{ Number of live births $(n=684)$} \\
\hline $0-2$ & 215 & 31.4 \\
\hline $3-5$ & 207 & 30.3 \\
\hline $6+$ & 262 & 38.3 \\
\hline \multicolumn{3}{|c|}{ Wish to have more children $(n=675)$} \\
\hline No & 232 & 34.4 \\
\hline Yes & 443 & 65.6 \\
\hline \multicolumn{3}{|c|}{ Number of additional children desired $(n=647)$} \\
\hline 0 & 232 & 35.9 \\
\hline $1-2$ & 250 & 38.6 \\
\hline$>2$ & 165 & 25.5 \\
\hline \multicolumn{3}{|c|}{ Decision-making for family planning use $(n=692)$} \\
\hline Self & 137 & 19.8 \\
\hline
\end{tabular}




\begin{tabular}{|lll|}
\hline Characteristics & Number & Percent \\
\hline Joint with partner & 555 & 80.2 \\
\hline Health post as the only accessible source for family planning & & \\
\hline No & 583 & 83.0 \\
Yes & 119 & 17.0 \\
\hline
\end{tabular}

Among the study participants, $22.6 \%$ were new to family planning. Of those with experience in family planning methods, $35.5 \%$ had a history of LARC use before the most recent one, primarily Implanon (75.0\%) and Jadelle (19.4\%). During the survey, $92.7 \%$ of the clients were using LARC inserted primarily by L4HEWs, and majority were using Implanon (58.3\%) followed by IUCDs (34.3\%). Decisions on what type of LARC to use were made either jointly by the client and her partner $(65.3 \%)$ or by the client alone $(31.3 \%)$. Reasons for using family planning methods were birth spacing $(65.3 \%)$, limiting the number of children (22.6\%), delaying fertility (10.7\%), and others (1.4\%).

\section{Risk factors of LARC use}

Among the clients, $15.4 \%$ received family planning methods different from their original preference. The main reasons for this discrepancy were provider's recommendations $(15.2 \%)$ and client's revision of preference after being counseled by providers $(75.2 \%)$. Majority of those who have revised their preferences after receiving counseling were Christians, literates, housewives, those who were using other family planning methods, new family planning users, and those who did not plan their last pregnancy. New LARC users who were given services by L4HEWs tended to be young, lived in urban areas, slightly more Muslim by religion, less likely to want more children, more likely to decide on contraception on their own, and have access to modern family planning that is less dependent on health posts and L4HEWs (Table 2). 
Table 2

Factors associated with new LARC use, $n=702$, Ethiopia

\begin{tabular}{|c|c|c|c|c|c|}
\hline Variable & Total & $\begin{array}{l}\text { Both first time } \\
\text { modern family } \\
\text { planning and LARC } \\
\text { user } \\
\text { Number }(\%)\end{array}$ & $\begin{array}{l}\text { Previous modern } \\
\text { family planning user } \\
\text { but new LARC user } \\
\text { Number (\%) }\end{array}$ & $\begin{array}{l}\text { Previous } \\
\text { LARC } \\
\text { user } \\
\text { Number } \\
(\%)\end{array}$ & $\begin{array}{l}P \\
\text { value } \\
\left(\mathrm{Chi}^{2}\right)\end{array}$ \\
\hline \multicolumn{6}{|c|}{ Age $(n=699)$} \\
\hline$<20$ & 19 & $13(68.4)$ & 6 (31.6) & $0(0.0)$ & $<.001$ \\
\hline $20-35$ & 488 & 119 (24.4) & $248(50.8)$ & $\begin{array}{l}121 \\
(24.8)\end{array}$ & \\
\hline$>35$ & 192 & 25 (13.0) & $95(49.5)$ & $\begin{array}{l}72 \\
(37.5)\end{array}$ & \\
\hline \multicolumn{6}{|l|}{ Religion } \\
\hline Christian & 418 & 77 (18.4) & $209(50.0)$ & $\begin{array}{l}132 \\
(31.6)\end{array}$ & 0.001 \\
\hline Muslim & 284 & $82(28.9)$ & 141 (49.7) & $\begin{array}{l}61 \\
(21.5)\end{array}$ & \\
\hline \multicolumn{6}{|l|}{ Occupation } \\
\hline Housewife & 368 & $64(17.4)$ & $198(53.8)$ & $\begin{array}{l}106 \\
(28.8)\end{array}$ & 0.007 \\
\hline Farmer & 219 & $59(26.9)$ & $98(44.8)$ & $\begin{array}{l}62 \\
(28.3)\end{array}$ & \\
\hline Other & 115 & 36 (31.3) & $54(47.0)$ & $\begin{array}{l}25 \\
(21.7)\end{array}$ & \\
\hline \multicolumn{6}{|c|}{ Past pregnancy } \\
\hline No & 17 & $9(52.9)$ & $8(47.1)$ & $0(0.0)$ & 0.003 \\
\hline Yes & 685 & 150 (21.9) & 342 (49.9) & $\begin{array}{l}193 \\
(28.2)\end{array}$ & \\
\hline \multicolumn{6}{|c|}{$\begin{array}{l}\text { Number of live } \\
\text { births }(n=684)\end{array}$} \\
\hline $0-2$ & 215 & $72(33.5)$ & 104 (48.4) & $\begin{array}{l}39 \\
(18.1)\end{array}$ & $<.001$ \\
\hline
\end{tabular}

\footnotetext{
*Christians, literates, housewives, mothers who did not want their last pregnancy, those who were using other modern contraception, and new LARC users were more likely to change their mind on their preferred method of choice.
} 


\begin{tabular}{|c|c|c|c|c|c|}
\hline Variable & Total & $\begin{array}{l}\text { Both first time } \\
\text { modern family } \\
\text { planning and LARC } \\
\text { user } \\
\text { Number }(\%)\end{array}$ & $\begin{array}{l}\text { Previous modern } \\
\text { family planning user } \\
\text { but new LARC user } \\
\text { Number (\%) }\end{array}$ & $\begin{array}{l}\text { Previous } \\
\text { LARC } \\
\text { user } \\
\text { Number } \\
\text { (\%) }\end{array}$ & $\begin{array}{l}P \\
\text { value } \\
\left(\mathrm{Chi}^{2}\right)\end{array}$ \\
\hline $3-5$ & 207 & $30(14.5)$ & $118(57.0)$ & $\begin{array}{l}59 \\
(28.5)\end{array}$ & \\
\hline $6+$ & 262 & $47(17.9)$ & $120(45.8)$ & $\begin{array}{l}95 \\
(36.3)\end{array}$ & \\
\hline \multicolumn{6}{|l|}{$\begin{array}{l}\text { Want more children } \\
(n=675)\end{array}$} \\
\hline No & 232 & $37(16.0)$ & $113(48.7)$ & $\begin{array}{l}82 \\
(35.3)\end{array}$ & 0.001 \\
\hline Yes & 443 & $111(25.1)$ & $226(51.0)$ & $\begin{array}{l}106 \\
(23.9)\end{array}$ & \\
\hline \multicolumn{6}{|l|}{$\begin{array}{l}\text { Additional children } \\
\text { desired }(n=647)\end{array}$} \\
\hline 0 & 232 & $37(16.0)$ & $82(35.3)$ & $\begin{array}{l}113 \\
(48.7)\end{array}$ & $\begin{array}{l}<.001 \\
0.00\end{array}$ \\
\hline $1-2$ & 250 & $45(18.0)$ & $74(29.6)$ & $\begin{array}{l}131 \\
(52.4)\end{array}$ & \\
\hline$>2$ & 165 & $52(31.5)$ & $28(17.0)$ & $\begin{array}{l}85 \\
(51.5)\end{array}$ & \\
\hline \multicolumn{6}{|l|}{$\begin{array}{l}\text { Decision to use } \\
\text { family planning (n } \\
=692 \text { ) }\end{array}$} \\
\hline Self & 137 & $45(32.9)$ & $47(34.3)$ & $\begin{array}{l}45 \\
(32.9)\end{array}$ & $\begin{array}{l}<.001 \\
0.00\end{array}$ \\
\hline Joint with partner & 555 & $113(20.4)$ & $296(53.3)$ & $\begin{array}{l}146 \\
(26.3)\end{array}$ & \\
\hline \multicolumn{6}{|l|}{$\begin{array}{l}\text { Access to family } \\
\text { planning only at } \\
\text { health post }\end{array}$} \\
\hline No & 583 & $121(20.8)$ & $301(51.6)$ & $\begin{array}{l}161 \\
(27.6)\end{array}$ & 0.022 \\
\hline Yes & 119 & 38 (31.9) & $49(41.2)$ & $\begin{array}{l}32 \\
(26.9)\end{array}$ & \\
\hline
\end{tabular}

*Christians, literates, housewives, mothers who did not want their last pregnancy, those who were using other modern contraception, and new LARC users were more likely to change their mind on their preferred method of choice. 


\begin{tabular}{|c|c|c|c|c|c|}
\hline Variable & Total & $\begin{array}{l}\text { Both first time } \\
\text { modern family } \\
\text { planning and LARC } \\
\text { user } \\
\text { Number (\%) }\end{array}$ & $\begin{array}{l}\text { Previous modern } \\
\text { family planning user } \\
\text { but new LARC user } \\
\text { Number (\%) }\end{array}$ & $\begin{array}{l}\text { Previous } \\
\text { LARC } \\
\text { user } \\
\text { Number } \\
(\%)\end{array}$ & $\begin{array}{l}P \\
\text { value } \\
\left(\text { Chi }^{2}\right)\end{array}$ \\
\hline \multicolumn{6}{|c|}{$\begin{array}{l}\text { Preferred method } \\
\text { of contraception ( } \mathrm{n} \\
=693 \text { ) }\end{array}$} \\
\hline No* & 106 & $14(9.0)$ & $73(20.9)$ & $\begin{array}{l}19 \\
(10.1)\end{array}$ & $\begin{array}{l}< \\
0.001\end{array}$ \\
\hline Yes & 587 & $142(91.0)$ & $276(79.1)$ & $\begin{array}{l}169 \\
(89.9)\end{array}$ & \\
\hline \multicolumn{6}{|c|}{$\begin{array}{l}{ }^{*} \text { Christians, literates, housewives, mothers who did not want their last pregnancy, those who were } \\
\text { using other modern contraception, and new LARC users were more likely to change their mind on their } \\
\text { preferred method of choice. }\end{array}$} \\
\hline
\end{tabular}

If the health posts did not exist, $17.0 \%$ reported that they would not be able to use family planning methods. Among those who would have been able to access other health facilities, $27.0 \%$ would do it without any challenge. For $56.7 \%$ of the clients, it would take them more than an hour to travel to another health facility although the cost of travel for $67.5 \%$ of the clients is less than 20 Ethiopian Birr. Health posts provided more access to illiterates, farmers, those with no history of abortion, and those not needing additional children.

\section{Client's knowledge, attitude, and service provision satisfaction with health posts}

About 471 (67.38\%) of the clients had good knowledge about implants. Family planning clients have positive attitudes with acceptable variability among the clients about LARC methods provided at health posts by L4HEWs were $687(98.28 \%)$. Majority $(92.8 \%, 641 / 691)$ of family planning clients were highly satisfied with the service they received in the health posts from L4HEWs (Fig. 1). Among the clients, $97.1 \%(672 / 692)$ would recommend other friends and family members to visit the health posts for LARC provision. Based on their own experience, $94.5 \%$ (653/691) would recommend long-acting family planning methods to their friends, 3.5\% (24/691) would not recommend them, and 2.1\% (14/691) were not sure about it.

\section{Effectiveness of LARC provision at health posts}

For the majority of the clients (627, 89.3\%), LARCs were used effectively although 75 (10.3\%) had some complaint about them, primarily about their side effects $(71,94.7 \%)$, being pregnant $(2,2.7 \%)$, and expulsion of the IUCD $(1,1.3 \%)$. There were no reported cases of perforation or infection. At the time of data collection for this study, 36 clients had LARCs removed. Specifically, none of the 39 Jadelle users, $3.8 \%$ (15/397) of Implanon users, and 3.5\% (8/231) of IUCD users had their LARCs removed within eight 
months of receiving the service. The four leading reasons for removal of LARC were the desire to have children $(13,36.1 \%)$, headache $(9,25 \%)$, arm pain $(7,19.4 \%)$, and fatigue $(4,11.1 \%)$.

\section{Discussion}

LARCs administered by HEWs in the current study were effective in preventing pregnancy with low removal and low expulsion, which is comparable with previous studies where the service was provided in health centers $[18,19]$. Level of discontinuation varied depending on the duration of follow-up, which for IUCD was $19.9 \%$ in a 10-year retrospective study in a university hospital in Nigeria [20], while it was $4.5 \%$ in a five-year retrospective study in the same country [21]. For implants, it reached as high as $24 \%$ in a retrospective study done in the United States [22] and even higher in Nigeria [19]. The most common reason for discontinuation of use in the current study was the desire to become pregnant, followed by menopause or side effects. When the reason for discontinuation was side effects, the rate of discontinuation was higher in the first year, and when the reason was the desire to become pregnant, it slightly increased with the length of follow-up [20,21, 23]. In our study, side effects accounted for most of the reasons for discontinuation. The maximum length of follow-up in the current study is eight months, and more discontinuation is likely for fertility reasons if the follow-up of the study participants was continued beyond this period.

Contraceptive prevalence has significantly improved in Ethiopia in the past decade [2, 24]. This change is partly attributed to the work of the health extension program through the delivery of health education, which is likely to have increased contraception awareness and the demand for LARCs [8, 25-27]. The finding of the current study is in line with these. The availability of health posts in short distances for the community staffed with HEWs improved access by reducing cost and time for the provision of LARCs and at times were the only outlets to access modern family planning. This is a significant finding of tasksharing because more qualified HEWs may further increase access through direct service delivery instead of just activities to raise awareness.

In the current study, new LARC acceptors were more likely to be empowered to decide on contraception use, and access to modern family planning is less dependent on health posts and L4HEWs. In such areas where there are alternative service providers, it may be cost-effective to engage empowered clients and relocate these resources to areas where alternative outlets are limited [28, 29].

Method mix in Ethiopia is improving slowly [2]. Injectable contraception slightly declined from $80 \%$ in 2011 to $70 \%$ in 2016 [8, 24]. Such skewed distribution of method use may be a reflection of availability and readiness of the health sector to provide other options [29]. In this study, from the facility performance report, mixed LARC methods increased by threefold over an eight-month period.

A study that assessed factors affecting LARC use in Nigeria, Ethiopia, and the Democratic Republic of Congo identified the lack of equipment, private room, and products as a cause for the limited provision of that option in the studied countries. In Ethiopia, $44 \%$ of sites assessed indicated that LARC was available along with other options [30]. When availability was coupled with capacity building to nurse providers, 
method uptake among new users and method shift improved [31-33]. Method shift was well demonstrated in the present study where both capacity building and the availability of equipment and supplies were ensured.

L4HEWs played a role in method choice mostly by giving information during counseling and direct recommendations in a small proportion of cases $[34,35]$. Significantly more clients are empowered to decide on what type of LARC to use on their own or at least to discuss it with their partners. This is the general trend where informed and empowered clients who know about LARCs and would like to space births tend to prefer them $[25,36]$. Other studies in rural areas have indicated that established gender norms make it impossible for a married woman to make decisions in fertility and family planning methods [37]. It is therefore important to keep addressing these issues whenever they are identified as challenges.

Most LARC users were satisfied with the method they were using although they experienced minor side effects. The low level of side effects in general and the extremely low level of severe side effects leading to discontinuation in the current study is in agreement with many previous studies [38-42]. Side effects are often an important reason to discontinue treatment $[43,44]$, and since patients who experienced them may develop negative attitudes toward these methods, it is important for providers to counsel clients on the major side effects and how they could be handled if they occur.

One of the strengths of this study is it assessed LARC delivery through L4HEWs in a setting where there are few studies or reports that document service delivery by L4HEWs. Its findings have a clear potential to serve as an evidence base to better implement task-sharing activities in Ethiopia. One of the limitations arises from its design. A retrospective cohort study design is open for recall bias in some of the data, which were collected by interviewing the respondents. Also, only a limited number of relevant variables could be examined compared to what could be done if the data were collected prospectively. However, the cohort nature of the design allows for a discussion of causal associations between exposure and outcome variables.

\section{Conclusion}

This study indicated that trained L4HEWs can serve as an alternative service delivery outlet at the health post level. Task-shifting from facility-based to community-based delivery of LARCs may be possible.

\section{Acronyms}

EDHS - Ethiopian Demographic and Health Survey

FP - Family Planning

HEP - Health Extension Program 
IUCD - Intra Uterine Contraceptive Device

LARC - Long Acting Reversible Contraceptives

L4HEW - Level 4 Health Extension Worker

SNNPR - Southern Nations Nationalities and Peoples Region

WHO - World Health Organization

\section{Declarations}

\section{Acknowledgment}

We extend our appreciation to data collectors, supervisors, and the study participants for their cooperation, and we would also like to thank the Ministry of Health for providing the necessary information. The research team is also grateful for the financial support provided by the David and Lucile Packard Foundation.

Ethics Approval and Consent to participate: Ethical clearance was obtained from the Institutional Health Research Ethics Review Committee of the Ethiopian Public Health Association. All participants were asked for their written consent prior to interviews. All interviews were done in private settings, and visual and auditory privacy was ensured. Any health issues encountered during data collection were linked to the nearest facility.

\section{Availability of Data and material:}

Data is available for sharing upon request.

\section{Author Contributions:}

Alula M. Teklu (AT) Awol Seid (AS), Kassahun Mormu (KM), Tesfa Demlew (TD), Ephrem Tekle (ET), Berhane Assefa (BA) Simegnew Alem (SA) Girmay Medhin (GM), Kesetebirhan Delele (KD), Teklemichael G. Tesfay (TT)

AT: conceptualization, proposal writing, data analysis, manuscript writing, reviews AS: Conceptualization, manuscript writing, reiews, KM: conceptualization, review, TD: conceptualization, manuscript wrting, ET: Conceptualization, proposal writing, review, BA: conceptualization, review, SA: conceptualization, review, GM: data analysis, KD: data management and data analysis, TT: data analysis, manuscript writing and review

\section{Competing Interests:}

None of the authors have any conflict of interst to declare. 


\section{References}

1. Central Statistical Agency: Population Projections for Ethiopia 2007-2037. $2013 .$.

2. Central Statistical Agency: Demographic and Health Survey 2016: Key Indicators Report. 2016.

3. Performance Monitoring and Accountability 2020: Ethiopia-R3. 2015.

4. Performance Monitoring and Accountability 2020: Ethiopia-R4. $2016 .$.

5. Performance Monitoring and Accountability 2020: Ethiopia-R1. 2014.

6. Performance Monitoring and Accountability 2020: Ethiopia-R2. 2014.

7. Intrahealth International: Contraceptive Implants Are Driving Big Gains in Access to Family Planning. 2018.

8. Central Statistical Agency and ICF: Ethiopia Demographic and Health Survey 2016: KeyIndicators Report. Addis Ababa, Ethiopia, and Rockville, Maryland, USA. CSA and ICF. 2016.

9. Ethiopian Statistical Agency: Demographic and health survey. 2011..

10. Federal Ministry of Health: National Strategy for Newborn and Child Survival in Ethiopia 2015(16)2019(20)..

11. Federal Democratic Republic Ethiopia: National guideline for family planning services in Ethiopia Addis Ababa, Ethiopia. 2011.

12. Federal Ministry of Health: Annual Performance Report. 2017.

13. Federal Ministry of Health: Implementation guideline of the LARC by L4HEW 2016.

14. World Health Organisation: Recommendations for Task Shifting of Family Planning Services. 2011..

15. Yilmaz S. Venugopal V: Local government discretion and accountability in Ethiopia. In.: International Center for Public Policy, Andrew Young School of Policy Studies, Georgia State University; 2008.

16. Federal Ministry of Health: Health Sector Transformation Plan. 2015.

17. Central Statistical Agency and ICF.: Ethiopia Demographic and Health Survey 2016: HIV Prevalence Report. Addis Ababa, Ethiopia, and Rockville, Maryland, USA. CSA and ICF. 2016.

18. Sanders J, Turok D, Royer P, Thompson I, Gawron L, Storck K: One-year continuation of copper or levonorgestrel intrauterine devices initiated at the time of emergency contraception. Contraception 2017, 96(2):99-105.

19. Pam V, Mutihir J, Nyango D, Shambe I, Egbodo C, Karshima J: Sociodemographic profiles and usedynamics of Jadelle (levonorgestrel) implant in Jos, Nigeria Nigerian Medical Journal: Journal of the Nigeria Medical Association 2016, 57(6):314.

20. Irinyenikan TA. Arowojolu A: Pattern of discontinuation of intrauterine copper T 380a at the University College Hospital, Ibadan: a ten-year review. The Nigerian Postgraduate Medical Journal 2013, 20(4):336-340..

21. Iklaki CU. Agbakwuru AU, Udo AE. Abeshi SE: Five-year review of copper T intrauterine device use at the University of Calabar Teaching Hospital, Calabar. Open Access Journal of Contraception 2015, 6:143. 
22. Law A, Liao L, Lin J, Yaldo A, Lynen R: Twelve-month discontinuation rates of levonorgestrel intrauterine system $13.5 \mathrm{mg}$ and subdermal etonogestrel implant in women aged 18-44: A retrospective claims database analysis. Contraception 2018.

23. Sharma M. Joshi S, Nagar O. Sharma A: Determinants of intrauterine contraceptive device discontinuation among Indian women. The Journal of Obstetrics and Gynecology of India 2014, 64(3):208-211..

24. Central Statistical Agency and ICF.: Ethiopia Demographic and Health Survey 2011: Key Indicators Report. Addis Ababa, Ethiopia. 2011.

25. Gebremariam A, Addissie A: Intention to use long acting and permanent contraceptive methods and factors affecting it among married women in Adigrat town, Tigray, Northern Ethiopia Reproductive Health 2014, 11(1):24.

26. Medhanyie A, Spigt M, Kifle Y, Schaay N, Sanders D, Blanco R, GeertJan D, Berhane Y: The role of health extension workers in improving utilization of maternal health services in rural areas in Ethiopia: a cross sectional study. BMC Health Services Research 2012, 12(1):352.

27. Sedlander E, Bingenheimer JB, Edberg MC, Rimal RN, Shaikh H, Munar W: Understanding modern contraception uptake in one Ethiopian community: a case study. Reproductive Health 2018, 15(1):111.

28. Tilahun Y, Mehta S, Zerihun H, Lew C, Brooks MI, Nigatu T, Hagos KL, Asnake M, Tasissa A, Ali S. Expanding access to the intrauterine device in public health facilities in Ethiopia: a mixed-methods study. Global Health: Science Practice 2016, 4(1):16-28.

29. The FP2020 Partnership: The Way Ahead 2016-2017. 2016.

30. Thanel K, Garfinkel D, Riley C, Esch K, Girma W, Kebede T, Kasongo G, Afolabi K, Kalamar A, Thurston S: Leveraging long acting reversible contraceptives to achieve FP2020 commitments in sub-Saharan Africa: The potential of implants. PloS One 2018, 13(4):e0195228..

31. Fikree FF. Abshiro WK, Mai MM. Hagos KL, Asnake M: Strengthening youth friendly health services through expanding method choice to include long-acting reversible contraceptives for Ethiopian youth. African Journal of Reproductive Health 2017, 21(3):37-48.

32. Zerfu TA, Ayele HT, Bogale TN: Effect of Deploying Trained Community Based Reproductive Health Nurses (CORN) on Long-Acting Reversible Contraception (LARC) Use in Rural Ethiopia: A Cluster Randomized Community Trial. Studies in Family Planning 2018.

33. Tilahun Y, Lew C, Belayihun B, Hagos KL, Asnake M: Improving contraceptive access, use, and method mix by task sharing Implanon insertion to frontline health workers: the experience of the Integrated Family Health Program in Ethiopia. Global Health: Science and Practice 2017:GHSP-D-1700215.

34. Wellings K, Brima N, Sadler K, Copas AJ, McDaid L, Mercer CH, McManus S, Stephenson J, Glasier A: Stopping and switching contraceptive methods: findings from Contessa, a prospective longitudinal study of women of reproductive age in England Contraception 2015, 91(1):57-66. 
35. Rubin SE. Felsher M, Korich F. Jacobs AM: Urban adolescents' and young adults' decision-making process around selection of intrauterine contraception. Journal of Pediatric and Adolescent Gynecology 2016, 29(3):234-239..

36. UNICEF: Women's Empowerment as a Determinant of Contraceptive use in Ethiopia. 2013..

37. Geleta D, Birhanu Z, Kaufman M, Temesgen $B$ : Gender norms and family planning decision-making among married men and women, rural Ethiopia: A qualitative study. Science Journal of Public Health 2015, 3(2):242-50.

38. Burke HM. Packer CA, Spector HL, Hubacher D: Opportunity, satisfaction and regret: trying long acting reversible contraception in a unique scientific circumstance. Women \& Health 2018.

39. Hubacher $\mathrm{D}$, Spector $\mathrm{H}$, Monteith $C$, Chen $P$-L: Not seeking yet trying long-acting reversible contraception: a 24-month randomized trial on continuation, unintended pregnancy and satisfaction. Contraception 2018, 97(6):524-532..

40. Verhaeghe J: Clinical practice. European Journal of Pediatrics 2012, 171(6):895-899.

41. dos Santos PdNS, Madden T, Omvig K. Peipert JF: Changes in body composition in women using long-acting reversible contraception. Contraception 2017, 95(4):382-389..

42. Modesto W, Bahamondes MV, Bahamondes L: A randomized clinical trial of the effect of intensive versus non-intensive counselling on discontinuation rates due to bleeding disturbances of three longacting reversible contraceptives. Human Reproduction 2014, 29(7):1393-1399..

43. Anguzu R, Tweheyo R, Sekandi JN, Zalwango V, Muhumuza C, Tusiime S, Serwadda D: Knowledge and attitudes towards use of long acting reversible contraceptives among women of reproductive age in Lubaga division, Kampala district, Uganda BMC Research Notes 2014, 7(1):153.

44. Nawal Saeed Banafa ASA-H, Yahyakhamis Almualm and Mona Omer Alkathiri: Knowledge and Attitude about Side Effect of Implanon (Implant) among Women Attend Primary. ACTA Scientific Medical Sciences 2017, 1(1)..

\section{Figures}




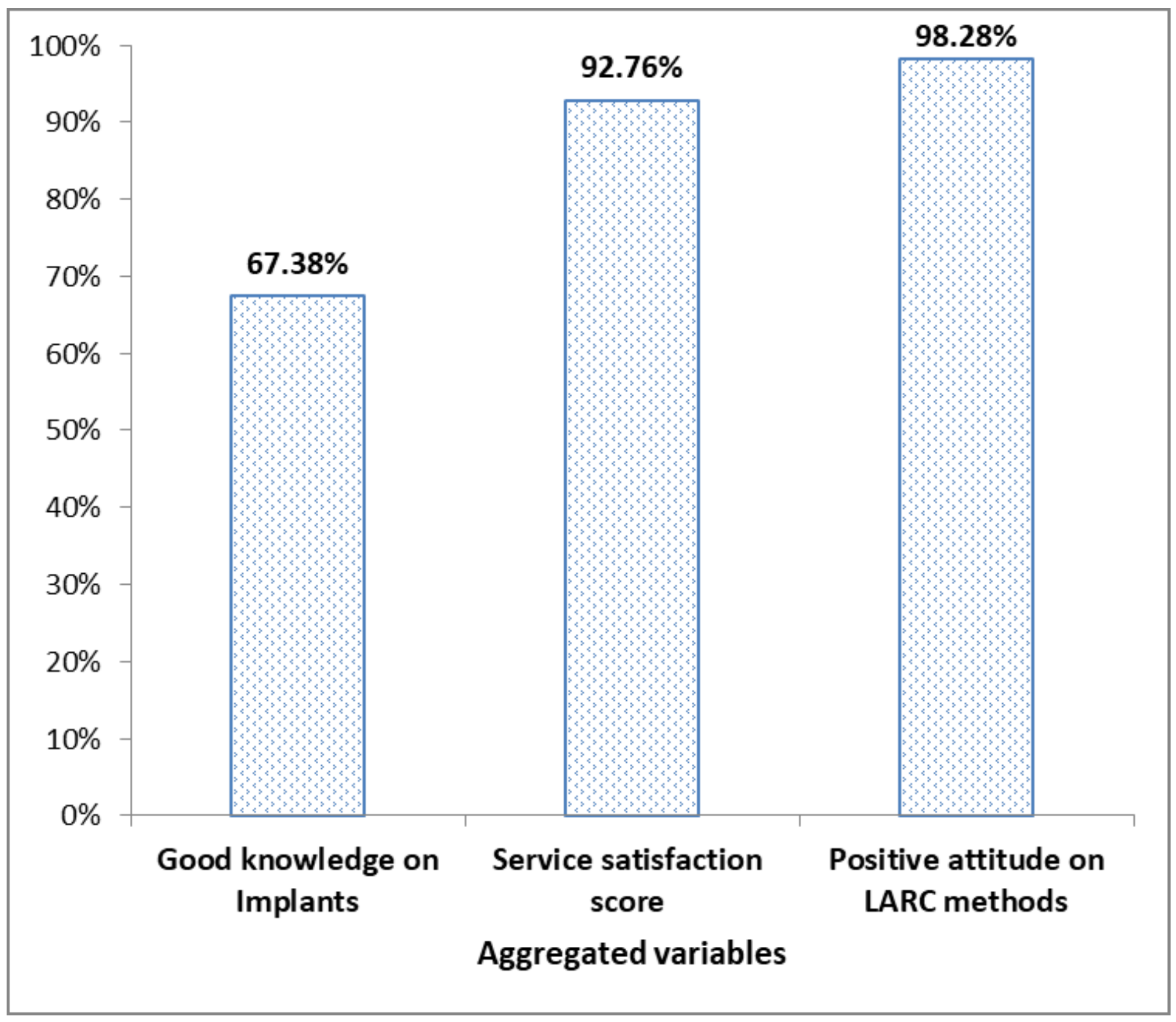

Figure 1

Knowledge and attitudes of clients about LARC methods and their satisfaction with the service provided at health posts, $n=702$, Ethiopia 